\title{
Geometry design in refractive capillary optical fibers
}

\author{
Ryszard S. Romaniuk* $^{*}$ \\ Institute of Electronic Systems, Warsaw University of Technology, Nowowiejska 15/19, 00-665 Warszawa,
}

Received May 04, 2010; accepted May 04, 2010; published June 30, 2010

\begin{abstract}
The work presents a design method of capillary optical fiber (COF) geometry. A change of proportions in the capillary optical fiber drawn from a single preform or a set of crucibles is allowed on-line via the control of overpressure and thermal conditions in the outflow meniscus, which essentially lowers the manufacturing costs. NavierStokes and Hagen-Poissuille equations, adapted to the COF pulling geometry, were solved. The velocity fields give solutions to other quantities of interest such as mass flow rate, pulling force and $\mathrm{COF}$ geometry, including controlled capillary expansion and collapse. The results for COFs are for the following dimensions: internal diameters 1$100 \mu \mathrm{m}$, external diameters $30-300 \mu \mathrm{m}$, dimensional stability $1 \%$. The major issue of the work is lowering capillary fiber fabrication costs.
\end{abstract}

A capillary optical fiber (COF) consists of an annular ring-like high-index optical core around an air hole, a low-index optical cladding and a protective, high-index polymer jacket. Optical wave propagation in a COF depends on the geometrical distribution of an empty area in the cross section of the fiber and refractive index distribution near the glass-air boundary. The refractive structure of the cladding is uniform or has index depression around the core. Fabrication techniques of a discrete COF differ for pure or high silica glasses and soft glasses and include: an MCVD preform with incomplete collapsing, hollow core preform or pressurized multicrucible [1-9]. A fiber of outside diameter $d_{f}$ is fabricated from a preform of outside diameter $d_{p}$.

Fiber geometry is created during the glass flow phase. The stationary dependence between the preform feed rate $\mathrm{v}_{\mathrm{p}}$ and the fiber pulling speed $\mathrm{v}_{\mathrm{f}}$ is $\mathrm{v}_{\mathrm{p}}=\mathrm{d}_{\mathrm{f}}^{2} \mathrm{v}_{\mathrm{f}} / \mathrm{d}_{\mathrm{p}}^{2}$. During the transient phase this dependence is functional $\mathrm{v}_{\mathrm{p}} \mathrm{d}_{\mathrm{p}}{ }^{2}=\mathrm{f}_{\mathrm{p}}(\mathrm{t})$, $\mathrm{v}_{\mathrm{f}} \mathrm{d}_{\mathrm{f}}^{2}=\mathrm{f}_{\mathrm{f}}(\mathrm{t})$. A high quality fiber requires the following condition to be fulfilled $\mathrm{v}_{\mathrm{p}} \mathrm{d}_{\mathrm{p}}{ }^{2}=\mathrm{v}_{\mathrm{f}} \mathrm{d}_{\mathrm{f}}{ }^{2}=$ const, or for fiber tapering $\mathrm{v}_{\mathrm{p}} \mathrm{d}_{\mathrm{p}}{ }^{2}=\mathrm{C}_{\mathrm{p}}=$ const, $\mathrm{v}_{\mathrm{f}} \mathrm{d}_{\mathrm{f}}^{2}=\mathrm{C}_{\mathrm{f}}=$ const. With a multilayered preform, the following condition is fulfilled $\Sigma(\mathrm{i}) \mathrm{v}_{\mathrm{pi}} \mathrm{d}_{\mathrm{pi}}{ }^{2}=\Sigma(\mathrm{i}) \mathrm{v}_{\mathrm{fi}} \mathrm{d}_{\mathrm{fi}}{ }^{2}$ [9]. Stationary condition means that the structure of a preform is imaged onto a fiber, assuming no shifts between glass layers. The above dependencies describe mass preservation while they do not include energy preservation. The whole system is fully described by the Navier-Stokes (N-S) equations. The diffusion-convection N-S state equations, transformed to fiber geometry presented in Fig.1, are

$$
\begin{gathered}
\rho\left(\mathrm{r}_{2}{ }^{2}-\mathrm{r}_{1}{ }^{2}\right)\left(\mathrm{v}_{\mathrm{t}}+\mathrm{vv}_{\mathrm{z}}-\mathrm{g}\right)=\left[3 \mu\left(\mathrm{r}_{2}{ }^{2}-\mathrm{r}_{1}{ }^{2}\right) \mathrm{v}_{\mathrm{z}}+\xi\left(\mathrm{r}_{1}+\mathrm{r}_{2}\right)\right]_{\mathrm{z}} \\
\left(\mathrm{r}_{1}{ }^{2}\right)_{\mathrm{t}}+\left(\mathrm{r}_{1}{ }^{2} \mathrm{v}\right)_{\mathrm{z}}=\left(\mathrm{r}_{2}{ }^{2}\right)_{\mathrm{t}}+\left(\mathrm{r}_{2}{ }^{2} \mathrm{v}\right)_{\mathrm{z}}=\left[\mathrm{p}_{\mathrm{o}} \mathrm{r}_{1}{ }^{2} \mathrm{r}_{1}{ }^{2}-\xi \mathrm{r}_{1} \mathrm{r}_{2}\left(\mathrm{r}_{1}+\mathrm{r}_{2}\right)\right] / \mu\left(\mathrm{r}_{2}{ }^{2}-\mathrm{r}_{1}{ }^{2}\right) \\
0.5\left(\mathrm{r}_{2}{ }^{2}-\mathrm{r}_{1}{ }^{2}\right)\left[\rho \mathrm{c}_{\mathrm{p}}\left(\mathrm{T}_{\mathrm{t}}+\mathrm{v} \mathrm{T}_{\mathrm{z}}\right)-\mathrm{k}\left(\mathrm{T}_{\mathrm{z}}\right)_{\mathrm{z}}-\sigma \varepsilon\left(\mathrm{T}_{\mathrm{a}}{ }^{4}-\mathrm{T}^{4}\right)\right]=\mathrm{r}_{2} \mathrm{~h}\left(\mathrm{~T}_{\mathrm{a}} \mathrm{-}-\mathrm{T}\right)
\end{gathered}
$$

${ }^{*}$ E-mail: rrom@ise.pw.edu.pl where subscripts $t$ and $z$ mean function derivatives, $t$-time, $z-$ distance, $r_{1}=r_{w}$ and $r_{2}=r_{z}$ are internal and external radius of capillary, v-velocity, $\rho$-density, g-gravitation, $\mu$-viscosity, $p_{0}-$ differential pressure, $\xi$-surface tension, $c_{p}$-heat capacity, Ttemp., $\mathrm{T}_{\mathrm{a}}$-ambient $\mathrm{T}$, k-heat conductance, $\sigma$-Stefan-Bolzman const., $\dot{\varepsilon}$-material emissivity constant, h-heat transfer coefficient.

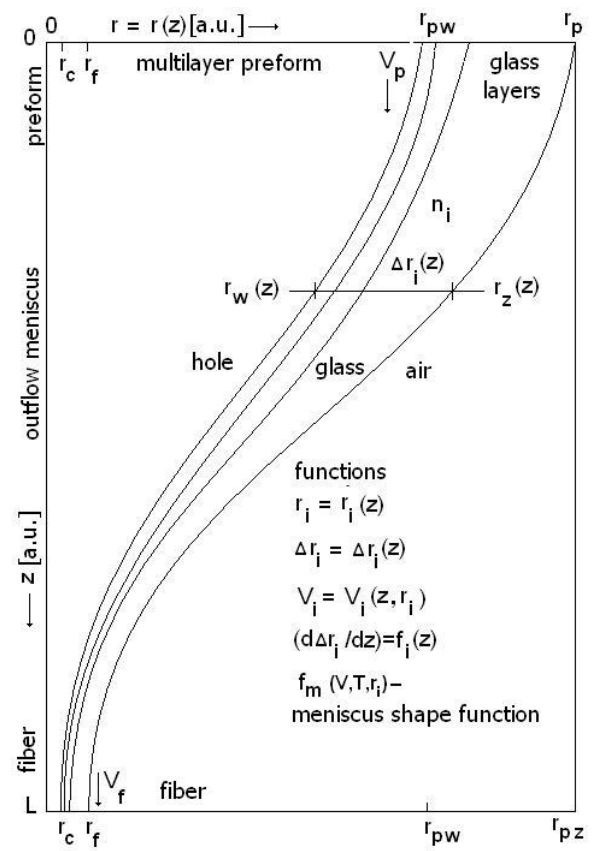

Fig.1. Geometry of a COF outflow meniscus (not to scale). $r_{p w}$-internal radius of a preform, $r_{\mathrm{pz}}$-external radius of a preform, L-length of a meniscus, $\mathrm{v}_{\mathrm{f}}$-rate of fiber pulling, $\mathrm{v}_{\mathrm{p}}$-preform feed ratio, $\mathrm{v}(\mathrm{z})$-velocity function, $\Delta \mathrm{r}_{\mathrm{i}}$-local thickness of a glass layer.

Mass and energy flow is caused by the preform feed of radius $r_{p}$ with rate $v_{p}$, meniscus heating, and fiber pulling of radius $r_{f}$ with rate $v_{f}$. The simplifying assumption is $\mathrm{r}_{\mathrm{f}}<<\mathrm{L}$, equivalent to slow mass outflow from the meniscus and temperature stability of the system. Normalized solutions to $\mathrm{N}-\mathrm{S}$ equations, in a form of velocity areas and derivatives - including temperature, mass flows and dimensions, are presented in Fig.2-4. Relative weights of the inertial gravitational surface tension and overpressure components are expressed by dimensionless numbers: $\quad \mathrm{R}_{\mathrm{i}}=\mathrm{Lv}_{\mathrm{f}} \rho / \mu, \quad \mathrm{R}_{\mathrm{g}}=\mathrm{gL}^{2} \rho \mu \mathrm{v}_{\mathrm{f}}$, $\mathrm{R}_{\mathrm{np}}=\xi \mathrm{L} / \mu \mathrm{r}_{\mathrm{c}} \mathrm{v}_{\mathrm{f}}, \mathrm{R}_{\mathrm{op}}=\mathrm{Lp}_{\mathrm{o}} / \mathrm{v}_{\mathrm{f}} \mu$ as well as capillary, Prandtl, Peclet and Biot. They can be calculated from the material and process data. The following ranges of the numbers 
for a fiber pulling process are assumed: $\mathrm{Ca}=\left(10^{2}-10^{4}\right)$, $\mathrm{Re}=(1-10), \quad \operatorname{Pr}=(1-300), \quad \mathrm{Pe}=\left(1-10^{3}\right), \quad \mathrm{Bi}=(0,01-0,05)$. $\mathrm{Bi}=0,01$ for thermally thin meniscus. This is usually not fulfilled, the $\mathrm{Bi}$ number is bigger and the meniscus is thermally thick (not isothermal).
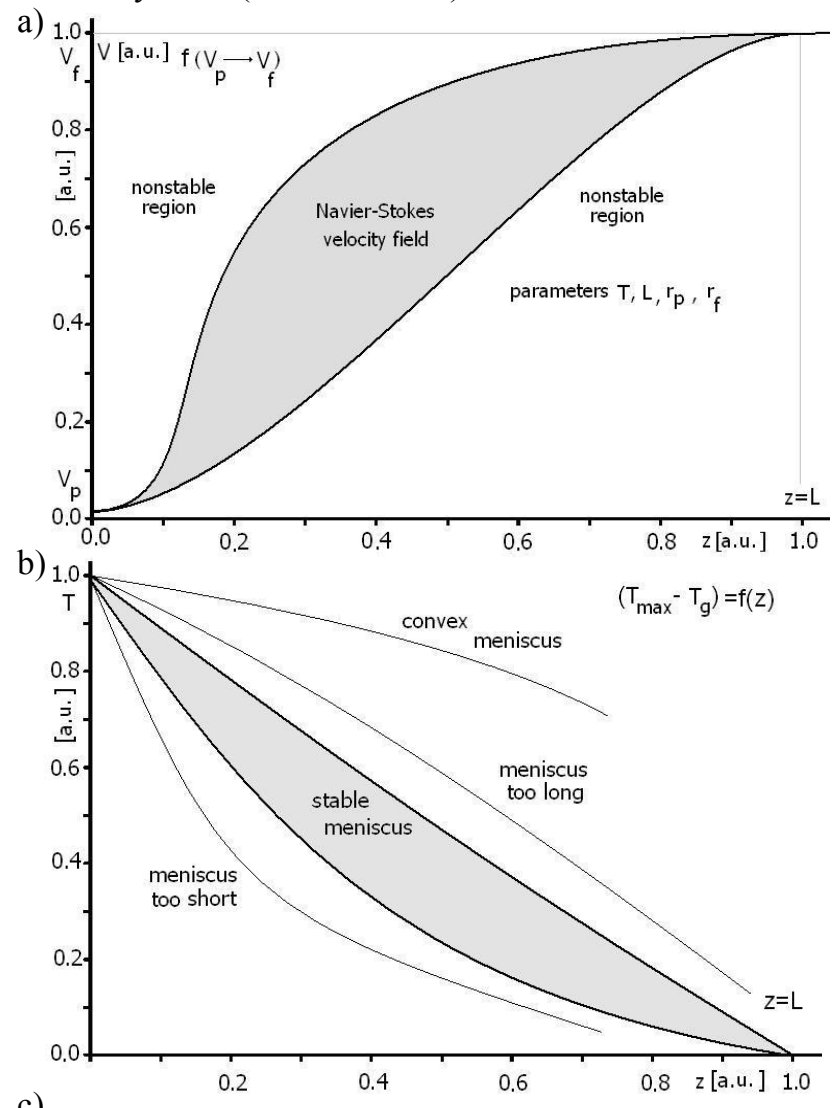

c)

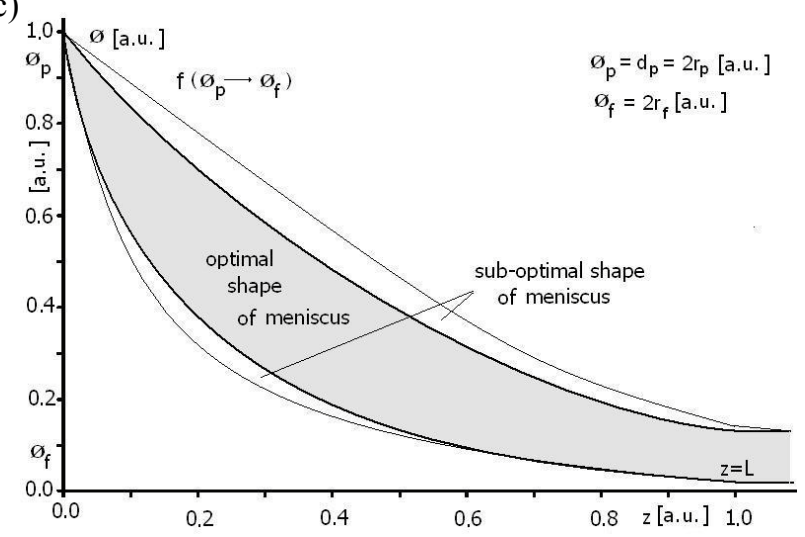

Fig. 2. Normalized parametric stationary solutions of the N-S equations for the meniscus region of a COF; (a) transformation of velocity $\mathrm{v}(\mathrm{z})$; (b) transformation of temperature $\mathrm{T}(\mathrm{z})$; (c) transformation of meniscus diameter.

Isothermal and inertia-less simplification leads to uncertainties of the process modelling smaller than $10 \%$. Assuming neither surface tension nor overpressure, the capillary is stationary. At high temperatures, with low surface tension, the viscosity dominates. Capillary collapsing depends on the ratio of $\xi / \mu$ and is more sensitive to $\mathrm{v}_{\mathrm{p}}$ than to $\mathrm{v}_{\mathrm{f}}$. Capillary collapsing is facilitated by high $\mathrm{T}$, low $\mu$, low $\mathrm{v}_{\mathrm{p}}$ and long $\mathrm{L}$.

a)

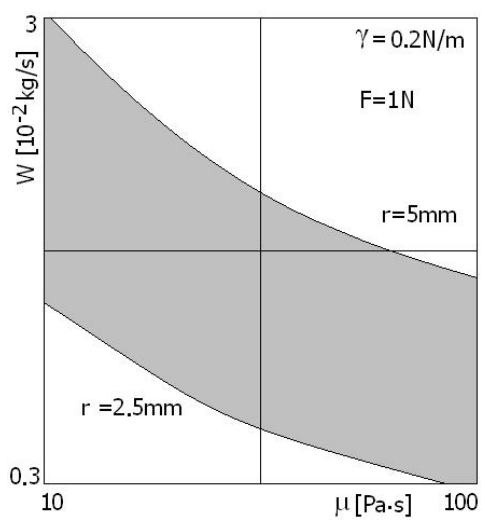

b)

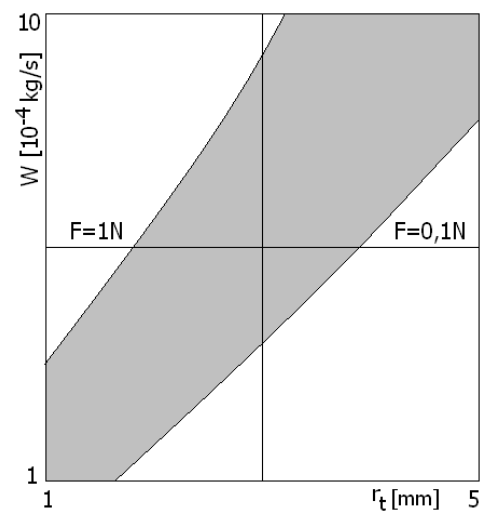

c)

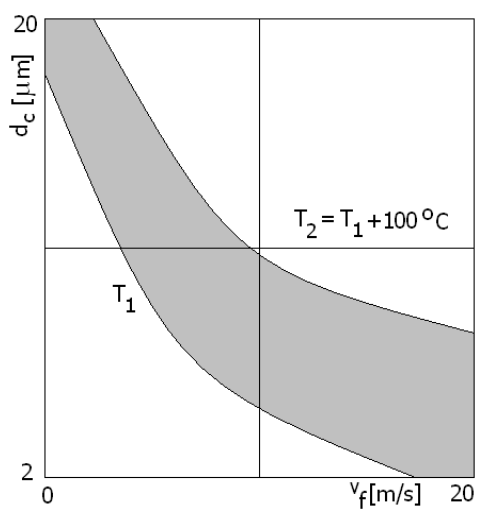

Fig. 3. Solutions to H-P equations for the COF pulling process. (a) Mass flow as a function of viscosity $\mathrm{W}(\mu)$ for an external crucible nozzle diameter change in the range $\mathrm{r}_{\mathrm{t}}=(2.5-5) \mathrm{mm}$ and pulling force $\mathrm{F}=1 \mathrm{~N}$. Surface tension in the upper meniscus assumed $\xi=0.2 \mathrm{~N} / \mathrm{m}$; (b) Mass flow as a function of the external nozzle diameter $\mathrm{r}_{\mathrm{t}}$, process data $\mu=100 \mathrm{~Pa} \mathrm{~s}, \gamma=0.2 \mathrm{~N} / \mathrm{m}, \mathrm{F}=0.1 \mathrm{~N}$; (c) Change in the capillary diameter as a function of the pulling rate for a temperature around the optimum.

Certain conditions favour the on-line changes of the COF geometry, thus, fabrication costs decrease. The sensitivity of the process to overpressure equals $\mathrm{S}=\mathrm{L} \xi / \mu \mathrm{r}_{\mathrm{p}} \mathrm{v}_{\mathrm{p}} \log \left(\mathrm{v}_{\mathrm{f}} / \mathrm{v}_{\mathrm{p}}\right)$. In the high temperature isothermal case, with large $L$ and low $v_{p}$, the $S<<1$, overpressure is an effective tool for geometry design. When $S>>1$ the system is too sensitive and the process is unstable. In a 
practical process, the $\mathrm{S}$ is a function of $\mu, \mathrm{T}, \mathrm{v}_{\mathrm{p}}, \mathrm{v}_{\mathrm{f}} / \mathrm{v}_{\mathrm{p}}$ and $\mathrm{r}_{\mathrm{pw}}$ because $\mathrm{L}$ and $\xi$ are almost constant. $\mathrm{S}$ increases for lower $\mathrm{T}$, smaller $\mathrm{r}_{\mathrm{c}}$, lower $\mathrm{v}_{\mathrm{p}}$ and $\mathrm{v}_{\mathrm{f}} / \mathrm{v}_{\mathrm{p}}$.

Such intermediate in-process parameters of the COF geometry as: meniscus length $\mathrm{L}$, distributions of meniscus shape $r(z)$, velocity $v(z)$, temperature $T(z)$ are among solutions of the N-S equations. The results were presented for realistic parameters of the process in the available pulling set-up. Figure $2 \mathrm{a}$ presents the area of stable monotonic functional evolution of $v_{p}$ to $v_{f}$. Individual velocity transformation curves for a particular process are within the grey area. Figure $2 \mathrm{~b}$ presents solutions for a normalized distribution of $\mathrm{T}$ in the meniscus zone. The distribution of $\mathrm{T}$ is determined by the oven temperature, glass mass flow, viscous dissipation and laminar flow of inertial gas. Viscous dissipation may have a big influence on $\mathrm{T}$ in the lower parts of the meniscus. Fig.2c presents the evolution of a local diameter of the meniscus $\phi=\mathrm{d}_{\mathrm{m}}(\mathrm{z})$. This function (which may have an inflection point) defines in which part of the meniscus the final form of a COF is determined. The location of an inflection point (or its absence) is a technological parameter.

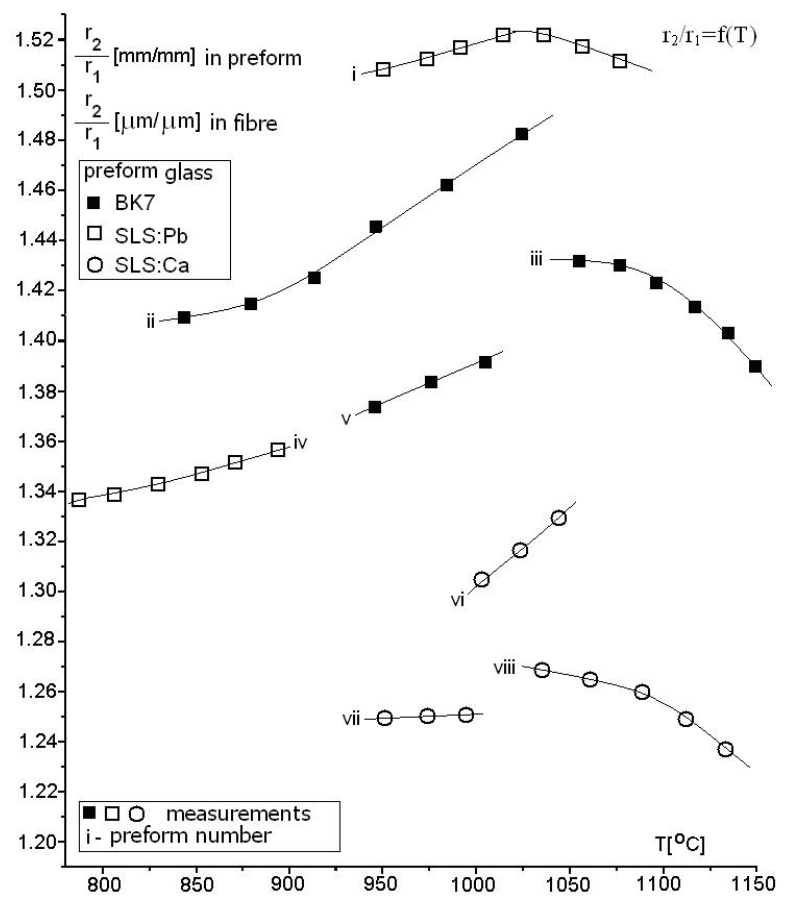

Fig. 4. Calculated and measured effect of capillary expansion (falling curve) or collapse (rising curve) $r_{2} / r_{1}=f(T)$ during fiber pulling from eight different soft glass tube-in-tube COF preforms.

The N-S equations are supplemented with HagenPoisseuille equations (H-P) to solve the proportions between the COF layers, which was presented in Fig. 4. The basic H-P equation is $\left.\mathrm{W}=\left(\pi \mathrm{R}^{4} \mathrm{~g} \Delta \mathrm{p}\right) /\left(8 \mu \mathrm{L}_{\mathrm{n}}\right)\right)=$ $\mathrm{S}(\mathrm{dh} / \mathrm{dt})$, where $\mathrm{W}$-volume flow, R-nozzle diameter, $\mathrm{L}_{\mathrm{n}^{-}}$ length of nozzle, S-effective surface of glass, h-height of fluid. The full set of H-P equations is:

$\mathrm{W}_{\mathrm{i}}=-\mathrm{S}_{\mathrm{i}}(\mathrm{dh} / \mathrm{dt})=\left(\pi \mathrm{R}_{\mathrm{i}}^{4} \mathrm{~g} / 8 \mu_{\mathrm{i}} \mathrm{L}_{\mathrm{i}}\right) \Sigma\left(\mathrm{h}_{\mathrm{i}} \rho_{\mathrm{i}}-\mathrm{h}_{\mathrm{j}} \rho_{\mathrm{j}}\right) \quad$ for $\quad(\mathrm{j}>\mathrm{i})$, $\mathrm{W}=\Sigma(\mathrm{i}) \mathrm{W}_{\mathrm{i}},(\mathrm{d} / \mathrm{dz})\left(\mathrm{W}^{2} / \pi \mathrm{dr}^{2}\right)=\mathrm{f}(\mathrm{r}, \mu, \xi, \rho)$ [9]. It is assumed here that pulling force, gravity and surface tension dominate in the upper part of a meniscus (high $\mathrm{T}$ ). The lower part of a meniscus (low $\mathrm{T}$ ) is dominated by viscosity and reaction with inertial gas. Some solutions to H-P equations were presented in Fig. 3 for eight different preforms. Preform data are published elsewhere [9].

To obtain a COF of the proportions imaging the preform (Fig.4) the process parameters should be as follows: the hot region in the oven shorter, small L, the smallest allowed $\mathrm{T}$ for a core-depression-cladding set of glasses, feed rate of preform $v_{p}$ large - lowering locally meniscus temperature, a preform and a fiber should have large holes. To obtain a COF of proportions distant from the preform, the process parameters should be essentially reverse: the hot region in the oven longer, $\mathrm{T}$ high and changeable, $\mathrm{v}_{\mathrm{p}}$ small, a preform with a large hole, fast feedback in $v_{f}$ control, meniscus cooling with an inertial gas, overpressure in a preform.

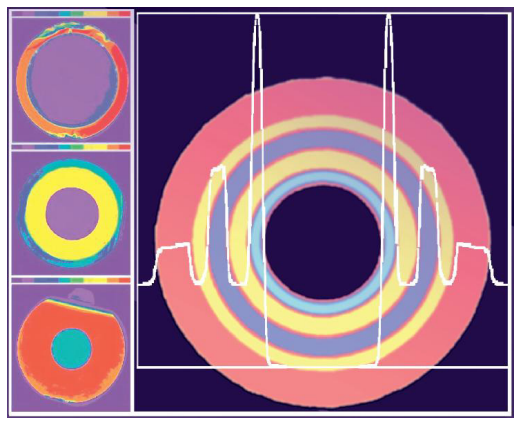

Fig. 5. Flase-color photo of end faces of COFs and one of its measured refractive index profile. COFs manufactured by the Dept. of Optical Fibers at the Białystok University of Technology. Courtesy of Prof. J.Dorosz.

Figure 5 presents the dimensional result changes in a COF fabricated from very similar multilayer preforms. Different fibers may be manufactured from a single preform, lowering the overall manufacturing costs. Very complex refractive structures may be manufactured too.

\section{References}

[1] Y.T. Shah, et al., Ind. Eng. Chem. Fund. 11, 150 (1972).

[2] B.P. Huynh, et al., Rheology Acta 22, 482 (1983).

[3] A.N. Beris, et al., J. Non-Newtonian Fluid Mechanics 26, 341 (1988).

[4] M. Myers, AIChE Journ. 35(4) 592 (1989).

[5] H. Papamichael, et al., J. Mater. Res. 6, 159 (1991).

[6] J.N. Dewynne, et al., Q. J. Mech. Appl. Math. 47, 541 (1994).

[7] A.D.Fitt, et al., JLT 19(12), 1924 (2001).

[8] A.D.Fitt, et al., Journ. of Engineering Mathematics 43(2) 201 (2002).

[9] R.Romaniuk, et al., ETQ PAS, 52(3), 451 (2006). 